\title{
Conserved peptide vaccine candidates containing multiple Ebola nucleoprotein epitopes display interactions with diverse HLA molecules
}

\author{
Sahil Jain ${ }^{1} \cdot$ Manoj Baranwal ${ }^{1}$ (D)
}

Received: 18 September 2018 / Accepted: 11 February 2019 / Published online: 21 February 2019

๑) Springer-Verlag GmbH Germany, part of Springer Nature 2019

\begin{abstract}
Immunoinformatics has come by leaps and bounds to finding potent vaccine candidates against various pathogens. In the current study, a combination of different $\mathrm{T}\left(\mathrm{CD} 4^{+}\right.$and $\left.\mathrm{CD} 8^{+}\right)$and $\mathrm{B}$ cell epitope prediction tools was applied to find peptides containing multiple epitopes against Ebola nucleoprotein (NP) and the presentation of peptides to human leukocyte antigen (HLA) molecules was analyzed by prediction, docking and population coverage tools. Further, potential peptides were analyzed by ELISA for peptide induced IFN- $\gamma$ secretion in peripheral blood mononuclear cells isolated from healthy volunteers. Six peptides were obtained after merging the overlapping multiple HLA I $\left(\mathrm{CD} 8^{+}\right)$and II $\left(\mathrm{CD} 4^{+}\right)$restricted T cell epitopes as well as B cell epitopes and eliminating the peptides liable to generate autoimmune and allergic response. All peptides displayed 100\% conservancy in Zaire ebolavirus. In other Ebola virus species (Sudan, Bundibugyo and Taï forest) and Filoviridae members (Lloviuvirus and Margburgvirus), some peptides were found to be conserved with minor variations. Prediction tools confirmed the ability of predicted peptides to bind with diverse HLA (HLA-A, HLA-B, HLA-DP, HLA-DQ and HLA-DR) alleles. CABS-dock results displayed that the average root mean square deviation (RMSD) value was less than three in majority of cases representing strong binding affinity with HLA alleles. Population coverage analysis predicted high coverage (>85\%) for expected immune response in four continents (Africa, America, Asia and Europe). Nine out of ten blood samples exhibited enhanced IFN- $\gamma$ secretion for two peptides (P2 and P3). Thus, the identified NP peptides can be considered as potential synthetic vaccine candidates against Ebola virus.
\end{abstract}

Keywords Epitope-based vaccine $\cdot$ Conservation analysis $\cdot$ HLA alleles $\cdot$ Molecular docking $\cdot$ Ebola nucleoprotein

\section{Introduction}

Ebolavirus (EBOV) is a Filoviridae member [1] responsible for Ebola virus disease (EVD) which leads to ungoverned viral replication and multi-organ failure [2]. The virus is known to multiply in various cell types (hepatocytes,

Edited by: Stephan Becker.

Electronic supplementary material The online version of this article (https://doi.org/10.1007/s00430-019-00584-y) contains supplementary material, which is available to authorized users.

Manoj Baranwal

manoj.baranwal@thapar.edu

1 Department of Biotechnology, Thapar Institute of Engineering and Technology, Patiala, Punjab 147004, India macrophages, endothelial and epithelial cells) and speedily makes its way into the vital organs of the host [3]. Maximum cases of EVD happen due to person to person transmission [4]. Approximately, 30,000 cases of Ebola have been reported till date since 1976 with North Kivu province being the site of latest outbreak in 2018 [5].

EBOV is a single non-segmented negative-stranded RNA virus with an unusual, variable-length, filamentous morphology. It consists of seven proteins viz. nucleoprotein (NP), polymerase cofactors (VP35 and VP40), glycoprotein (GP), transcription activators (VP30 and VP24) and RNA-dependent RNA polymerase (L) [6]. Like its family members, EBOV RNA is incapable of existing in naked form [7]. Nucleoprotein (NP) serves as scaffold for assembly of filovirus nucleocapsid (NC) which includes VP35, V30, VP24 and L [8]. NP interacts with VP35 and VP30 [8] which in turn interact with polymerase and help in assembling viral replication complex [9]. NC plays role 
in viral RNA synthesis during proliferation cycle [10-12]. Therefore, NP is essential in viral RNA synthesis and virus assembly [10] as ssRNA binding is likely dependent on oligomerization and proper orientation of NP $[10,11]$. NP also protects the virus from host innate immune responses and provides resistance to host ribonucleases. When NPspecific CTLs were given to naive mice challenged with a lethal EBOV dose, they helped to induce protection against EBOV indicating the role of cell-mediated immunity against NP [13]. In other recent study, analysis of T cell response was carried out for seven proteins of EBOV in 30 individuals who survived after EBOV infection and it was observed that the maximum survivors (96\%) responded against the NP protein as compared to other proteins [14]. Hence, NP is a highly critical protein and, thus, presents itself as a lucrative vaccine design target.

Vaccine development against EBOV is still in development phase and various trials include viral vector-based vaccines [15], protein-based vaccines [16] and subunit vaccines [17]. In recent years, there has been a remarkable progress in peptide-based vaccines which are fragments of protein antigen sequences assembled into a single molecule capable of inducing an immune response. Immunoinformatics tools have shown success in elucidating potent peptide vaccine candidates against influenza virus [18], hepatitis C [19], West Nile virus [20] and EBOV [21]. The immunogenic peptides obtained using this approach were validated in in vitro system for influenza [22] and in in vivo system for Brucella abortus [23] and EBOV [24].

In the present investigation, peptides containing multiple epitopes against EBOV NP were selected based on different epitope prediction tools and examined for their conservation among the EBOV species and other Filoviridae members. These peptides were looked for binding potential to diverse HLA molecules based on different prediction tools, docking and population coverage analysis. Further, in vitro validation of immunogenic response of three potential peptides was carried out by measuring IFN- $\gamma$ secreted by peptide-stimulated peripheral blood mononuclear cells (PBMC) isolated from healthy blood samples.

\section{Method}

\section{Conserved peptides identification}

195 unique Ebola nucleoprotein sequences (739 amino acids) out of a total of 2407 entries (1976-May 2018) were downloaded from viprbrc and NCBI databases. These sequences comprised 187 (Zaire), five (Sudan), two (Bundibugyo) and one (Taï Forest) sequences belonging to various Ebola species pathogenic to humans. MUSCLE [25] and AVANA [26] tools were employed to identify peptide fragments showing at least $90 \%$ conservancy.

\section{Prediction of T and B cell epitopes}

$\mathrm{T}$ cell epitopes were predicted based on a consensus approach [27] that includes three prediction tools (SYFPEITHI, NetCTL 1.2 and IEDB consensus) for $\mathrm{CD}^{+} \mathrm{T}$ cell epitopes (HLA class I) and three tools (MHC2Pred, Propred and IEDB consensus) for $\mathrm{CD}^{+}{ }^{+} \mathrm{T}$ cell epitopes (HLA class II). The detailed information of each tool is mentioned in Table 1. The epitopes showing overlaps were further joined to obtain peptide fragments containing both $\mathrm{CD} 4^{+}$and $\mathrm{CD} 8^{+}$ $\mathrm{T}$ cell epitopes.

Linear, 10 amino acid long B cell epitopes were identified with the help of ABCpred at default threshold (0.51). This tool utilizes a recurring neural network method to predict $\mathrm{B}$ cell epitopes with $65.93 \%$ accuracy [33].

\section{Screening of peptides for autoimmune and allergic response}

Peptides having seven out of nine consecutive amino acids identical to human proteome were eliminated using BLAST analysis. Allergenicity of the peptides was predicted using the online tool AlgPred, which is based on screening $\operatorname{IgE}$ epitopes in query protein sequence and Motif Alignment \& Search Tool [34].
Table 1 T cell epitope prediction tools

\begin{tabular}{lllll}
\hline T cell & Tools & Algorithm & Threshold & Reference \\
\hline $\mathrm{CD}^{+}$ & SYFPEITHI & Motifs search approach & 20 & Rammensee et al. [28] \\
& NetCTL 1.2 & Weight-matrix method & 0.75 & Larsen et al. [29] \\
& IEDB consensus & Artificial neural network & $\mathrm{IC}_{50}<500 \mathrm{~nm}$ & Nielsen et al. [30] \\
$\mathrm{CD}^{+}$ & MHC2Pred & $\begin{array}{c}\text { Support vector machine } \\
\text { (SVM) method }\end{array}$ & 0.5 & Bhasin et al. [31] \\
& & Quantitative matrices & $3 \%$ & Singh et al. [32] \\
& Propred & Artificial neural network & $\mathrm{IC}_{50}<500 \mathrm{~nm}$ & Nielsen et al. [30] \\
\hline
\end{tabular}




\section{Conservancy analysis amongst Ebola species and other filoviridae members}

The identified peptides were looked for conservancy in human-pathogenic Ebola species (Zaire, Sudan, Bundibugyo and Taï forest) sequences as well as in 18 unique out of a total of 79 Marburgvirus nucleoprotein sequences and the only available unique nucleoprotein sequence of Lloviuvirus obtained from viprbrc and NCBI databases.

\section{Molecular docking}

HLA-peptide interaction analysis was done with the help of CABS-dock which allows for flexibility of peptide and receptor backbone [35]. High-resolution crystal structures of eighteen HLA class I and II alleles (nine each) bound to their respective native peptide were obtained from PDB. The HLA crystal structures without their native peptides (peptides already bound to the HLA) were obtained using Discovery Studio Visualizer (version 4.1). RMSD values obtained by docking the native peptides to their respective HLA structures served as standard. Peptides showing RMSD $>5$ or found to be interacting outside the binding groove were eliminated.

\section{Population coverage analysis}

IEDB population coverage analysis tool, based on peptideHLA data and HLA genotypic frequency, plays an important role in a bid to develop a globally protective vaccine. The selected peptides and their HLA alleles obtained from prediction tools were used as input for this tool. For this analysis, four different geographical continents (Africa, America, Asia and Europe) were chosen. Africa, America and Asia comprised 13 different geographical regions and, therefore, the average of population coverage for these regions was considered. Analysis was also carried out by taking into account the whole world.

\section{Statistical analysis}

One-way Anova followed by Tukey's multiple comparison test using GraphPad Prism was carried out to analyze the docking data.

\section{Measurement of IFN- $\gamma$ secreted by peptide-stimulated peripheral blood mononuclear cells}

P2, P3 and P5 were commercially synthesized by GL Biochem (Shanghai) Ltd. Healthy blood samples were obtained from Nitin Hospital, Patiala and Rajindra Hospital, Patiala (India) after informed consent from all volunteers. The study was approved by the institutional ethical committee. Peripheral blood mononuclear cells (PBMC) were isolated via ficoll density gradient method [22]. Restimulation assay was carried out for measuring peptide-induced IFN- $\gamma$ secretion with certain modifications to the previous report [36]. In a 96-well cell culture plate, $2 \times 10^{5}$ cells were seeded per well in a total volume of $200 \mu \mathrm{L}$ complete media (RPMI1640 supplemented with $10 \%$ fetal bovine serum, $100 \mu \mathrm{g} / \mathrm{mL}$ streptomycin, 100 I.U./mL penicillin and $10 \mathrm{mM}$ HEPES) and stimulated with each peptide $(50 \mu \mathrm{g} / \mathrm{mL})$. Unstimulated cells served as negative control while cells stimulated with $10 \mu \mathrm{g} / \mathrm{mL}$ of concanavalin A (ConA, Sigma-Aldrich) served as positive control. Restimulation was done on 3rd day with each peptide. On 5th day, IFN- $\gamma$ secreted by unstimulated, peptide-stimulated and ConA-stimulated cells was measured by performing ELISA with the help of human IFN- $\gamma$ mini Elisa development kit (Peprotech, USA). A microplate reader (Tecan Austria) was used to take absorbance at $405 \mathrm{~nm}$ with $630 \mathrm{~nm}$ as reference wavelength. All experiments were carried out in triplicates. IFN- $\gamma$ production was expressed as fold change which is the ratio of absorbance of peptide-stimulated cells and unstimulated cells.

\section{Results}

\section{Conserved peptides containing $\mathrm{T}$ and $\mathrm{B}$ cell epitopes and having no autoimmune and allergic properties}

Four overlapping fragments $(\mathrm{C} 1-\mathrm{C} 4)$ with $\geq 90 \%$ conservancy in 195 Ebola nucleoprotein sequences were obtained after multiple sequence alignment via MUSCLE and conservancy analysis via AVANA (Online Resource 1). Next, epitopes commonly predicted in the identified fragments by six epitope prediction tools (three each for HLA class I and II) were considered. Initially, 105 and 79 HLA class I (CD8 ${ }^{+}$ $\mathrm{T}$ cell) and II $\left(\mathrm{CD}^{+}{ }^{+} \mathrm{T}\right.$ cell $)$ binding epitopes were obtained, respectively (Online Resource 2). Twelve peptide fragments containing multiple $\mathrm{CD} 8^{+}$and $\mathrm{CD} 4^{+} \mathrm{T}$ cell epitopes were obtained by merging overlapping epitopes (Online Resource $3)$.

A total of 201 linear B cell epitopes were obtained after analyzing the four conserved fragments $(\mathrm{C} 1-\mathrm{C} 4)$ via ABCpred (Online Resource 2). The predicted B cell epitopes were present only in eight identified fragments. These eight peptides were checked for autoimmune and allergic responses. Two peptide fragments (VGHMMVIFRLMRTNFLIKFLLIHQGMHMV and YAPFARLLNLSGV) exhibited similarity to intrinsic human proteins based on BLAST analysis and, hence, were eliminated. Algpred tool confirmed none of the peptides to be allergic in nature. Thus, six non-self and non-allergic peptide candidates possessing multiple B and $\mathrm{T}$ cell epitopes were selected (Table 2). 
Table 2 Peptides representing the presence of different $\mathrm{T}$ and $B$ cell epitopes

\begin{tabular}{|c|c|c|c|}
\hline Peptide fragments & $\mathrm{CD}^{+}$epitopes & $\mathrm{CD} 4^{+}$epitopes & B-cell epitopes \\
\hline MDYHKILTAGL (P1) & YHKILTAGL & $\begin{array}{l}\text { MDYHKILTA } \\
\text { YHKILTAGL }\end{array}$ & DYHKILTAGL \\
\hline IVRQRVIPVYQVNNLEEI (P2) & $\begin{array}{l}\text { IVRQRVIPV } \\
\text { VRQRVIPVY } \\
\text { IPVYQVNNL } \\
\text { YQVNNLEEI }\end{array}$ & $\begin{array}{l}\text { IVRQRVIPV } \\
\text { IPVYQVNNL } \\
\text { VYQVNNLEE } \\
\text { YQVNNLEEI }\end{array}$ & $\begin{array}{l}\text { VYQVNNLEEI } \\
\text { RVIPVYQVNN } \\
\text { RQRVIPVYQV }\end{array}$ \\
\hline FLSFASLFLPKL (P3) & $\begin{array}{l}\text { FLSFASLFL } \\
\text { SFASLFLPK } \\
\text { FASLFLPKL }\end{array}$ & FLSFASLFL & $\begin{array}{l}\text { FLSFASLFLP } \\
\text { LSFASLFLPK }\end{array}$ \\
\hline ERGVRLHPLARTAK (P4) & $\begin{array}{l}\text { ERGVRLHPL } \\
\text { GVRLHPLAR }\end{array}$ & $\begin{array}{l}\text { LHPLARTAK } \\
\text { VRLHPLART }\end{array}$ & $\begin{array}{l}\text { RLHPLARTAK } \\
\text { ERGVRLHPLA } \\
\text { VRLHPLARTA }\end{array}$ \\
\hline LFPQLSAIALGVATAHGS (P5) & $\begin{array}{l}\text { FPQLSAIAL } \\
\text { QLSAIALGV }\end{array}$ & $\begin{array}{l}\text { LFPQLSAIA } \\
\text { FPQLSAIAL } \\
\text { LGVATAHGS }\end{array}$ & $\begin{array}{l}\text { AIALGVATAH } \\
\text { LSAIALGVAT } \\
\text { FPQLSAIALG } \\
\text { ALGVATAHGS } \\
\text { QLSAIALGVA }\end{array}$ \\
\hline VLYYHMMKDEPVVF (P6) & HMMKDEPVV & $\begin{array}{l}\text { VLYYHMMKD } \\
\text { LYYHMMKDE } \\
\text { YHMMKDEPV } \\
\text { MMKDEPVVF }\end{array}$ & $\begin{array}{l}\text { YHMMKDEPVV } \\
\text { VLYYHMMKDE } \\
\text { HMMKDEPVVF }\end{array}$ \\
\hline
\end{tabular}

\section{Conservation analysis of peptides amongst different Ebola virus species and related family members}

Six identified fragments were investigated for their conservancy in different species of Ebola virus (Zaire, Sudan, Bundibugyo and Taï Forest) and other members (Marburgvirus and Lloviuvirus) of Filoviridae to judge the potential of these candidates to develop cross protective immunity. Interestingly, all selected peptides showed $100 \%$ conservancy amongst Zaire ebolavirus nucleoprotein sequences (Table 3). P3 was found to be $100 \%$ conserved in all Ebola virus species and Lloviuvirus and there was a single amino acid variation in case of Marburgvirus. P5 was found to be $100 \%$ conserved in three Ebola virus species (Zaire, Bundibugyo and Taï Forest) while one amino acid variation at same position was observed in Sudan, Lloviu and Marburg viruses (Table 3). Rest of the peptides were found with few variations in different Ebola virus species. In most cases, one

Table 3 Peptide conservation in Ebola virus species and other filoviridae members

\begin{tabular}{|c|c|c|c|c|c|c|}
\hline Virus species & $\begin{array}{l}\text { MDYHKILT- } \\
\text { AGL (P1) }\end{array}$ & $\begin{array}{l}\text { IVRQRVIPVYQVNN- } \\
\text { LEEI (P2) }\end{array}$ & $\begin{array}{l}\text { FLSFA- } \\
\text { SLFLPKL } \\
(\mathrm{P} 3)\end{array}$ & ERGVRLHPLARTAK (P4) & $\begin{array}{l}\text { LFPQLSAIALG- } \\
\text { VATAHGS (P5) }\end{array}$ & $\begin{array}{l}\text { VLYYHM- } \\
\text { MKDEPVVF } \\
\text { (P6) }\end{array}$ \\
\hline ZAIRE & $100 \%$ & $100 \%$ & $100 \%$ & $100 \%$ & $100 \%$ & $100 \%$ \\
\hline${ }^{\mathrm{a}}$ SUDAN & $\begin{array}{l}\text { LDYHKILT- } \\
\text { AGL }\end{array}$ & 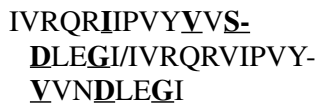 & $100 \%$ & $\underline{\text { DLGVRLHPLARTAK }}$ & $\begin{array}{l}\text { LYYPQLSAIALG- } \\
\text { VATAHGS }\end{array}$ & $\begin{array}{l}\underline{\text { INYYHLMS- }} \\
\text { DEPIAF }\end{array}$ \\
\hline TAÏ FOREST & $\begin{array}{l}\text { TDYHKILT- } \\
\text { AGL }\end{array}$ & $\begin{array}{l}\text { IVRQRVIQVHQVTN- } \\
\text { LEEI }\end{array}$ & $100 \%$ & EHGVRLHPLARTAK & $100 \%$ & $\begin{array}{l}\text { ILYYYMM- } \\
\text { MTEEPIVF }\end{array}$ \\
\hline BUNDIBUGYO & $\begin{array}{l}\underline{\text { ADYHKILT- }} \\
\text { AGL }\end{array}$ & IVRQRIIPVYQISNLEEV & $100 \%$ & EHGVRLHPLARTAK & $100 \%$ & $\begin{array}{l}\text { ILYYHM- } \\
\text { MKEEPIIF }\end{array}$ \\
\hline LLOVIU & & & $100 \%$ & EAGGQLLHPLARTSKK & $\begin{array}{l}\text { LYPQLSAIALG- } \\
\text { VATAHGS }\end{array}$ & \\
\hline${ }^{\mathrm{a}}$ MARBURG & & & $\begin{array}{l}\text { FLSFCSS- } \\
\text { LFLPKL }\end{array}$ & 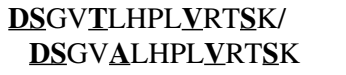 & $\begin{array}{l}\text { LYYPQLSAIALG- } \\
\text { VATAHGS }\end{array}$ & \\
\hline
\end{tabular}

${ }^{\mathrm{a}} \mathrm{P} 2$ and $\mathrm{P} 4$ of Sudan and Marburg virus, respectively, have two variable sequences 
Table 4 Peptides containing multiple epitopes binding to diverse HLA alleles

\begin{tabular}{|c|c|c|c|c|c|c|c|c|c|c|c|c|}
\hline \multirow{3}{*}{$\begin{array}{l}\text { Tools } \\
\text { HLA type }\end{array}$} & \multicolumn{6}{|c|}{ Class I } & \multicolumn{6}{|l|}{ Class II } \\
\hline & \multicolumn{2}{|c|}{ SYFPEITHI } & \multicolumn{2}{|c|}{ NetCTL 1.2} & \multicolumn{2}{|c|}{ IEDB } & \multirow{2}{*}{$\begin{array}{l}\text { ProPred } \\
\text { DR }\end{array}$} & \multicolumn{2}{|c|}{ MHC2Pred } & \multicolumn{3}{|c|}{ IEDB } \\
\hline & A & B & A & B & A & B & & DQ & DR & DP & DQ & DR \\
\hline Number $^{\mathrm{a}}$ & 7 & 26 & 5 & 7 & 18 & 32 & 51 & 11 & 27 & 5 & 6 & 14 \\
\hline $\begin{array}{l}\text { MDYHKILTAGL } \\
\text { (P1) }\end{array}$ & - & 4 & - & 2 & - & 1 & 22 & 5 & 5 & - & 1 & 10 \\
\hline $\begin{array}{l}\text { IVRQRVIPVY- } \\
\text { QVNNLEEI (P2) }\end{array}$ & 1 & 5 & 1 & 5 & 5 & 6 & 51 & 9 & 18 & 3 & 2 & 14 \\
\hline $\begin{array}{l}\text { FLSFASLFLPKL } \\
\text { (P3) }\end{array}$ & 3 & 2 & 3 & 1 & 9 & - & 18 & 2 & 4 & 5 & 1 & 7 \\
\hline $\begin{array}{l}\text { ERGVRLH- } \\
\text { PLARTAK (P4) }\end{array}$ & 3 & 5 & 1 & 1 & 2 & 3 & 24 & - & 7 & - & 1 & 7 \\
\hline $\begin{array}{l}\text { LFPQLSAIALGVA- } \\
\text { TAHGS (P5) }\end{array}$ & 2 & 4 & 1 & 3 & 3 & 6 & 15 & 3 & 6 & 1 & 2 & 10 \\
\hline $\begin{array}{l}\text { VLYYHMMK- } \\
\text { DEPVVF (P6) }\end{array}$ & 1 & - & 1 & - & 2 & - & 18 & 4 & 7 & 4 & 2 & 13 \\
\hline
\end{tabular}

**Both alleles and supertypes (a supertype is a group consisting of similar alleles) have been mentioned in this table. A complete list of alleles predicted by various computational tools for all the identified peptides has been provided (Online Resource 4)

${ }^{a}$ Total number of HLA alleles/supertypes in each tool

variable sequence was observed but P2 (Sudan ebolavirus) and P4 (Marburgvirus) were found to be with two variable sequences (Table 3). P1, P2 and P6 could not be located in NP sequence of Lloviu and Marburg viruses.

\section{Peptide-HLA interactions}

Peptides are presented by HLA molecules to induce immune response and HLA polymorphism is well known [37, 38]. Therefore, it is desirable for potent peptide vaccine candidates to exhibit interaction with a wide range of HLA molecules. During epitope prediction, all HLA alleles/supertypes available in various tools (Table 4) were considered. All selected peptides were found to bind with diverse and large number of HLA alleles which are of HLA-A, HLA-B, HLA-DP, HLA-DQ and HLA-DR types (Table 4) and the complete detail of HLA restrictions of all peptides has been mentioned (Online Resource 4). P2, P3 and P5 peptides were found to be predicted for most HLA types (Table 4) as well as maximum number of HLA alleles (Online Resource 4).

Docking study gives a wider prospective to understand the actual binding interaction of peptides with HLA molecules. Eighteen HLA alleles belonging to different HLA categories were chosen for docking with CABS-dock. Crystal structures for eighteen HLA alleles were obtained from PDB and native peptides, ranging from 8 to 11 residues in length for HLA class I and 9-20 residues in length for HLA class II, were separated using Discovery studio Visualizer 4.1. Nonamer $\mathrm{CD} 8^{+} \mathrm{T}$ cell epitopes which are part of selected six peptides (Table 2) were docked with HLA class
I molecules as the binding groove of HLA class I is closed and can accommodate $8-10$ residue peptides. HLA class II has open grooves and is capable of presenting 13-25 residue peptides; thus, six peptides as such were docked with class II molecules [39]. RMSD values (CABS-dock) obtained by docking native peptides to their respective HLA molecules were used as test control.

The average of RMSD values of $\mathrm{CD} 8^{+} \mathrm{T}$ cell epitopes (HLA class I) which are associated with respective peptide is plotted in Fig. 1. The models with RMSD value $<3$ are considered high-quality predictions while those with $3 \leq \mathrm{RMSD} \geq 5.5$ as moderate quality predictions [40]. In some HLA-peptide interactions such as P1 (B*1801 and DRB*0101), P4-DQ8 and P6-DQ8, the RMSD value was $>5$ showing poor quality prediction and, hence, these values were not plotted. In majority of the cases, the RMSD value was less than 3 for peptide-HLA (class I and II) (Fig. 1). The mean and median RMSD value of each peptide was also found to be less than 3 which confirmed the strong binding interaction of predicted peptide with eighteen HLA molecules (Table 5). It was observed that RMSD values of all peptides were not significantly different from native peptides and also within the range of native peptides with few variations. The majority of RMSD data display either positive skewness or a skewness value close to zero (normal distribution) indicating stable interactions between a greater number of HLA alleles and identified peptides. P2, P4 and P6 displayed negative skewness for HLA class I indicating a highly stable interaction between them and only a few HLA class I alleles while these peptides displayed positive skewness for HLA class II alleles. Based on mean binding energy, 

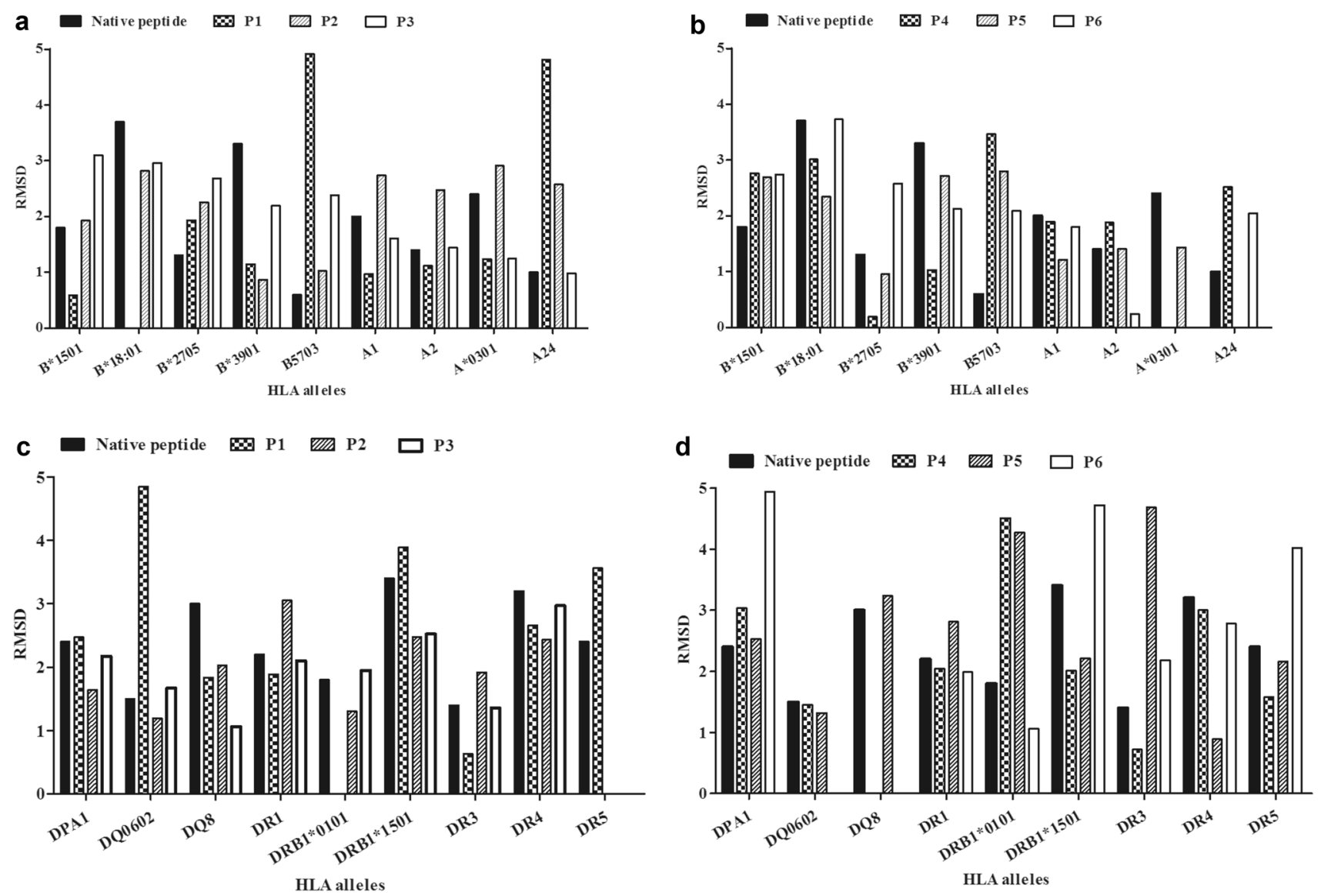

Fig. 1 RMSD of the native peptide (NP) and identified Ebola nucleoprotein peptides obtained by CABS-dock analysis. For HLA class I, RMSD of a Native peptide, P1 P2 and P3 peptides and b Native peptide, P4, P5 and P6 peptides. For HLA class II, RMSD of $\mathbf{c}$ Native peptide, P1, P2 and P3 peptides and d Native peptide, P4, P5 and P6 peptides. For $\mathbf{a}$ and $\mathbf{b}$, the mean RMSD of epitopes belonging to the respective peptide was considered except for peptides consisting of a

P5 displayed best interaction with HLA class I molecules amongst the identified peptides while P2 and P3 displayed better interaction ability with HLA class II molecules as compared to native peptides (Table 5).

In addition to docking and HLA coverage in tools, population coverage analysis was carried out which provides the expected response of the peptides to various HLA molecules in different geographic regions. Encouraging results were observed as the all peptides exhibited more than $95 \%$ coverage for American, Asian and European populations (Fig. 2) and the expected response was found to be $90-100 \%$ when the analysis was done by taking whole world. The average of response for each peptide to four continents (Africa, America, Asia and Europe) comprising 14 total geographical areas was P1 (94.7\%), P2 (96\%), P3 (95.4\%), P4 (85\%), P5 (95\%) and P6 (94.3\%).

single $\mathrm{CD}^{+} \mathrm{T}$ cell specific epitope (P1 and P6). For $\mathbf{c}$ and $\mathbf{d}, \mathrm{RMSD}$ value obtained after docking-identified peptides with various HLA alleles was considered. Native peptides represent the peptide that already existed in the crystallographic structures of the HLA molecules. They were separated and docked with their respective HLA molecule. RMSD values found to be $>5$ represent poor quality predictions and, hence, they were not plotted

\section{Mapping of peptide fragments}

P2-P5 were found to be located in the core domain of NP protein. $\mathrm{P} 1$ was found to be near the $\mathrm{N}$ tail of the protein while $\mathrm{P} 6$ was found to be a part of $\mathrm{C}$ tail (Fig. 3).

\section{Peptide-induced IFN- $\gamma$ secretion}

Three peptides (P2, P3 and P5) performed better during docking analysis as well as exhibited greater HLA allele coverage. Hence, these peptides were tested in vitro to validate their immunogenic potential. PBMC isolated from healthy blood samples were incubated as such (unstimulated cells), with peptides (peptide-stimulated cells) and ConA (positive control). 9 out of 10 samples showed enhanced IFN- $\gamma$ secretion (fold change $>=1.0$ ) for peptide-stimulated cells in case of P2 and P3. P5 was less responsive as only 2 out of 10 samples clearly showed enhanced IFN- $\gamma$ secretions as 
Table 5 Comparative analysis of RMSD value (CABS-Dock) of selected peptides with native peptides

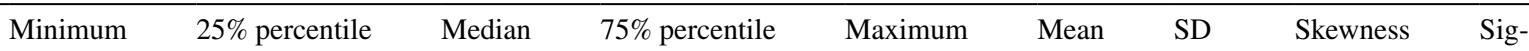

\begin{tabular}{|c|c|c|c|c|c|c|c|c|c|}
\hline \multicolumn{10}{|c|}{ Class I } \\
\hline NP & 0.60 & 1.15 & 1.80 & 2.85 & 3.70 & 1.94 & 1.03 & 0.62 & \\
\hline $\mathrm{P} 1$ & 0.60 & 1.02 & 1.20 & 4.07 & 4.90 & 2.08 & 1.74 & 1.27 & ns \\
\hline $\mathrm{P} 2$ & 0.90 & 1.45 & 2.50 & 2.75 & 2.90 & 2.16 & 0.75 & -1.01 & ns \\
\hline P3 & 1.0 & 1.30 & 2.20 & 2.85 & 3.10 & 2.06 & 0.79 & -0.01 & $\mathrm{~ns}$ \\
\hline $\mathrm{P} 4$ & 0.20 & 1.40 & 1.90 & 2.90 & 3.50 & 2.06 & 1.02 & -0.52 & $\mathrm{~ns}$ \\
\hline P5 & 1.0 & 1.25 & 1.90 & 2.70 & 2.80 & 1.95 & 0.76 & -0.02 & ns \\
\hline P6 & 0.20 & 1.87 & 2.10 & 2.67 & 3.70 & 2.16 & 0.98 & -0.73 & $\mathrm{~ns}$ \\
\hline \multicolumn{10}{|c|}{ Class II } \\
\hline $\mathrm{NP}$ & 1.40 & 1.65 & 2.40 & 3.10 & 3.40 & 2.36 & 0.72 & 0.08 & \\
\hline $\mathrm{P} 1$ & 0.60 & 1.82 & 2.60 & 3.82 & 4.90 & 2.73 & 1.36 & 0.08 & ns \\
\hline $\mathrm{P} 2$ & 1.20 & 1.37 & 1.95 & 2.47 & 3.10 & 2.00 & 0.64 & 0.42 & ns \\
\hline $\mathrm{P} 3$ & 1.10 & 1.47 & 2.05 & 2.42 & 3.00 & 2.00 & 0.60 & 0.13 & ns \\
\hline $\mathrm{P} 4$ & 0.70 & 1.52 & 2.00 & 3.00 & 4.50 & 2.28 & 1.17 & 0.78 & ns \\
\hline $\mathrm{P} 5$ & 0.90 & 1.75 & 2.50 & 3.75 & 4.70 & 2.67 & 1.25 & 0.34 & $\mathrm{~ns}$ \\
\hline P6 & 1.10 & 2.00 & 2.80 & 4.70 & 4.90 & 3.10 & 1.45 & 0.04 & ns \\
\hline
\end{tabular}

$N P$ native peptide (Peptides which were bound to the PDB HLA structure)

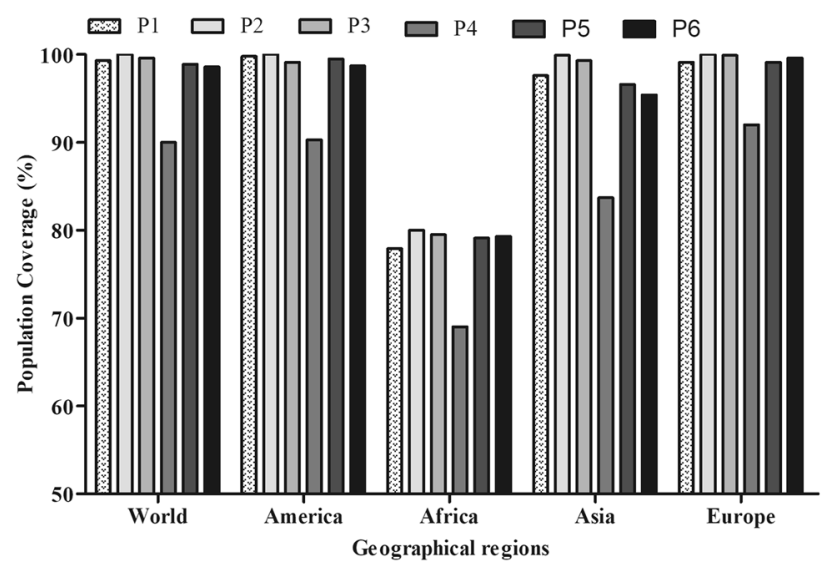

Fig. 2 Population coverage of the identified peptides in four different continents and whole world. The mean population coverage for three different geographical continents (America, Africa and Asia) has been plotted compared to unstimulated cells (Fig. 4). ConA-treated cells showed more IFN- $\gamma$ production for all the samples.

\section{Discussion}

Peptides as a choice for vaccine formulation is one of the recent developments and many peptide-based vaccines are in different stages of clinical trials. More than ten anti-cancer peptide vaccine candidates have made it to phase III trials [41]. Phase II trials are being conducted for peptide vaccines against influenza [42] and HPV-induced cancer [43]. Relying solely on in vitro or in vivo analysis for immunogenic peptide identification is cumbersome and not feasible in all facilities around the world. Computational immunology offers advantages in downsizing the number of peptide candidate to be validated in vitro or in vivo. In the current study, six EBOV NP peptides containing multiple epitopes having potential to interact with an array of HLA molecules were identified. Numerous computational works have been done in identifying epitopes against different infectious organisms
Fig. 3 Schematic presentation of identified peptides in different regions of Ebola nucleoprotein

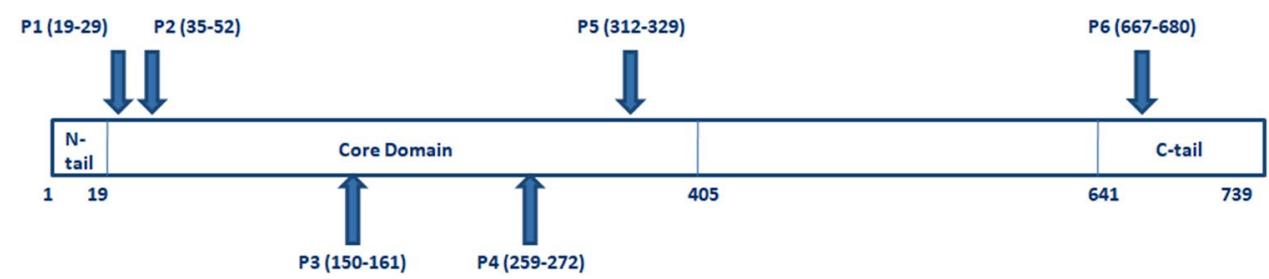



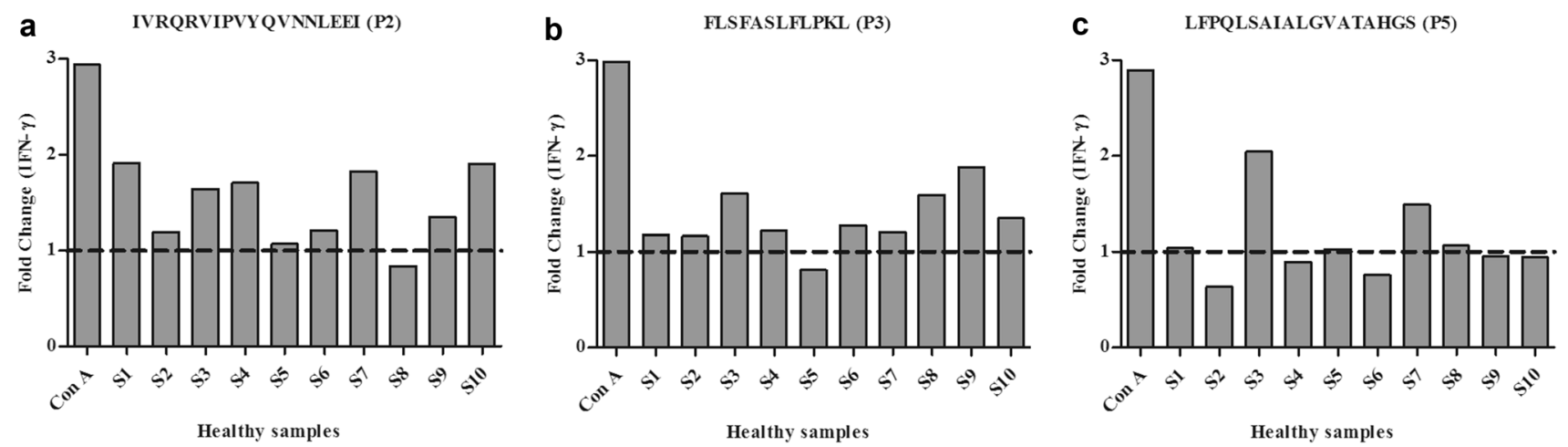

Fig. 4 IFN- $\gamma$ secretion by peripheral blood mononuclear cells of 10 healthy blood samples has been presented and expressed as fold change for a P2, b P3 and c P5. Fold change is the ratio of absorbance of peptide-stimulated cells and unstimulated cells. S1-S10 represent the 10 healthy blood samples. ConA:Concanavalin A such as Leishmania [44], Mycobacterium tuberculosis [45] and influenza virus [46]. Immunoinformatically identified peptides have shown enhanced proliferation and IFN- $\gamma$ production in peptide-induced peripheral blood mononuclear cells [22]. Also, in vivo validation of computationally generated peptide vaccine candidates with mice as subject for Leishmania donovani [47], Moraxella catarrhalis [48] and Brucella abortus [23] showed promising results. Hence, computational identification of potential peptide vaccine candidates against different infections has picked pace in recent years. EBOV represents a serious concern for human health and, thus, with the application of various computational tools, six EBOV NP peptides containing multiple $\mathrm{T}$ and $\mathrm{B}$ cell epitopes were designed. Owing to the presence of different epitopes, these peptides may be capable of generating both humoral and cell-mediated immunity.

One of the interesting aspects of this study is the usage of consensus approach in which six prediction tools (three each for $\mathrm{CD}^{+}$and $\mathrm{CD}^{+}{ }^{+} \mathrm{T}$ cell epitopes) were employed. The advantage of consensus approach is consideration of multiple prediction algorithms, immunological factors and databases in predicting the epitopes. In contrast to the present study, Sundar et al. used one prediction tool [49] while two prediction tools were used by Dutta et al. [50]. An approach similar to the current study was employed by Dikhit et al. where three different prediction algorithms were used to define only $\mathrm{CD} 8^{+} \mathrm{T}$ cell epitopes but not $\mathrm{CD} 4^{+} \mathrm{T}$ cell epitopes [51]. In all these studies [49-51], the work was carried out only for identifying $\mathrm{CD} 8^{+} \mathrm{T}$ cell epitopes. The present study focuses on the identification of peptides containing both $\mathrm{CD} 8^{+}$and $\mathrm{CD} 4^{+} \mathrm{T}$ cell epitopes. Further, in contrast to previous studies [49-51] where protein sequences were taken from single EBOV strain, the present study has considered the sequences from 1976 to May 2018 of all EBOV strains infecting humans. The conserved sequences obtained from 195 unique Ebola nucleoprotein sequences were taken for predicting the epitopes.

As per the comparative analysis performed with the help of IEDB, none of the six peptide fragments were found to be reported exactly in any of the previous studies. YQVNNLEEI, FLSFASLFL and FPQLSAIAL are the partial fragments of $\mathrm{P} 2$, P3 and $\mathrm{P} 5$ peptides, respectively (Table 2), that have been reported to induce $\mathrm{CD} 8^{+} \mathrm{T}$ cell response in earlier studies [49, 52-55]. In another study, mice injected with EBOV NP vaccine responded by producing protective CTLs against VYQVNNLEEIC (consisting of a part of P2) [56]. A large peptide sequence, HILRSQGPFDAVLYYHMMKDEPVVFSTSDGKEYTYP (consisting of P6), was reported to induce $\mathrm{CD}^{+} \mathrm{T}$ cell response in human survivors [14].

Any component of a vaccine may contribute to adverse effects after vaccine administration [57]. There is a chance of autoimmune reactions after vaccination [58]. Association of polyarthritis and thrombocytopenia with hepatitis B vaccine administration has been reported [59]. Also, neural complications on administering anti-rabies and tetanus vaccinations have been presented in previous studies [60]. Hence, BLAST analysis was applied in the current study to remove potential autoimmune response elucidators. VGHMMVIFRLMRTNFLIKFLLIHQGMHMV was eliminated owing to its similarity to human Anaphase-promoting complex/cyclosome and YAPFARLLNLSGV was eliminated as it showed similarity to homeobox protein, Hox-B9. Angioedema, bronchospasm, shock and a drop in blood pressure are some of the allergic responses to vaccines [57]. Measles-Mumps-Rubella (MMR) vaccination has been reported to induce anaphylactic reactions in some individuals and has been a subject of great debate for administration to egg allergic children $[61,62]$. Current in silico analysis established that all peptides under consideration were incapable of inducing any allergic responses. 
To validate the in silico selected peptides in the in vitro system, three peptides were checked for IFN- $\gamma$ secretion in peptide-stimulated PBMC. In previous studies also, extracellular release of IFN- $\gamma$ to represent antigen-induced proliferation of $\mathrm{T}$ cells has been measured by ELISA [22, 63, 64]. Interestingly, nine out of ten samples responded with enhanced IFN- $\gamma$ production for two peptides (P2 and P3), thus validating the immunogenic potential of these computationally identified peptides.

Conservation analysis presented a wider prospective to identify peptide candidates which may have the potential to provide immunity against existing and future viral strains as well as cross protective immunity. As per various previous studies, 36-351 residues (P2-P5 lie in this polypeptide) are highly conserved amongst all EBOV strains, Marburgvirus as well as Lloviuvirus [11] belonging to the same family (Filoviridae) and other Mononegavirales members such as respiratory syncytial virus [65], Nipah virus [66] and Parainfluenza virus 5 [67] have shown structural similarity to EBOV. The identified peptides have shown conservation and similarity with EBOV species and other filovirus (Marburgvirus and Lloviuvirus) but not with other Mononegavirales members. Interestingly, all selected peptides were $100 \%$ conserved amongst Zaire ebolavirus strains. Further, P3 and P5 were conserved (100\%) in most human infecting Ebola species and considered filoviridae members barring a single amino acid variation in a few species. These results supported the idea of development of cross-protective peptide vaccine.

One of the challenges in the development of peptidebased vaccine is to identify peptide candidates which provide immunity to different populations across the world. Adaptive immune response is directly associated with peptides presented by HLA molecules which are highly polymorphic. 13,680 HLA I and 5091 HLA II alleles belonging to different populations of the world have been reported in IPD-IMGT/HLA Database (release version 3.33, July 2018) $[68,69]$. Peptide selection in the current study was done by accounting for multiple epitopes which provide opportunity to include large number of HLA alleles belonging to HLA-A, HLA-B, HLA-DP, HLA-DQ and HLA-DR. Further, docking studies have been carried out previously to ascertain the same in case of influenza virus and human baculo virus $[18,70]$. Docking analysis was also carried out for EBOV epitopes with only HLA A0201 allele earlier [51]. In the current study, high-resolution nine PDB protein structures, each of HLA class I and II belonging to different HLA alleles, were considered. Statistical analysis indicated that the average RMSD value of selected peptides was not significantly different from that of native peptides indicating their similar binding potential. Moreover, RMSD value is less than 3 in most of the cases indicating highly favorable binding interactions with selected HLA molecules. Population coverage analysis was employed as an additional computational tool to judge the expected immune response of peptides in different geographical populations. Average population coverage lied in the range $90-100 \%$ for America, Asia, Europe and whole world which further confirmed the potential of the selected peptides as global vaccine candidates.

Further, these peptides were found to be parts of crucial nucleoprotein domains. P1-P5 are a part of $\mathrm{N}$ terminal 1-450 residues, a polypeptide which in itself is sufficient for viral genome replication [71]. P2-P5 are a part of N-terminal 36-351 residues which are needed for NP oligomerization and RNA binding [12]. Most of P1 form an oligomerization arm of NP [11]. A part of P1 lies in N-terminal 1-24 residues which enhance ssRNA binding as well as control NP intermolecular interactions [10, 12]. One residue of P3 (160th) is amongst the four important nucleoprotein residues $(160,171,174$ and 248) responsible for RNA encapsidation [72] and their deletion impairs EBOV replication [73]. Residues of P4 and P5 (264, 268 and 316) are involved in the formation of a highly conserved hydrophobic pocket significant for RNA formation [12].

Vaccine development against EBOV is in progress and nearly eight ebola vaccines candidates have made it to clinical trials [74]. A replication competent vesicular stomatitis virus vector-based vaccine named rVSV $\Delta$ G-ZEBOV-GP has shown encouraging results in random and non-random trials conducted in Guinea, West Africa [75] and was proven to be effective with tolerable side effects [76]. Another vaccine named ChAd3-EBO is a non-replicating chimpanzee adenovirus vector-based vaccine which has exhibited efficacy in non-human primates [77] and an increased response with a modified vaccinia Ankara (MVA) booster [78]. Although some EBOV vaccines are in clinical trials, there is still a long way to reach the market. Peptides identified in this study offer advantages of being small molecules with a potential to provide immunity against all EBOV strains and other filoviruses and, hence, might be considered for designing a globally protective vaccine.

\section{Conclusion}

Six non-self and non-allergic peptides having multiple $\mathrm{T}$ and B cell epitopes were obtained and found to be $100 \%$ conserved in Zaire EBOV species. These peptides were predicted for diverse HLA alleles and found to have strong binding affinity with eighteen different HLA molecules. Also, the peptides exhibited strong population coverage among the different geographical regions across the globe. Two out of three potential peptides tested for in vitro immune response showed enhanced IFN- $\gamma$ production for peptide-stimulated PBMC. Thus, these peptides are proposed to be validated further to inculcate these peptides in design of a synthetic peptide vaccine against EBOV and related species. 
Acknowledgements We express our sincere thanks to the scientific community for developing in silico tools. We also express our gratitude towards Dr. Akshey Jain and Dr. Vandana Singla for providing us blood samples of healthy volunteers.

\section{Compliance with ethical standards}

Conflict of interest All authors declare that they have no conflict of interest.

\section{References}

1. Kuhn JH, Becker S, Ebihara H et al (2010) Proposal for a revised taxonomy of the family Filoviridae: classification, names of taxa and viruses, and virus abbreviations. Arch Virol 155(12):2083-2103

2. Lee JE, Fusco ML, Hessell AJ, Oswald WB, Burton DR, Saphire EO (2008) Structure of the Ebola virus glycoprotein bound to an antibody from a human survivor. Nature 454(7201):177-182

3. Sanchez A, Lukwiya M, Bausch D, Mahanty S, Sanchez AJ, Wagoner KD, Rollin PE (2004) Analysis of human peripheral blood samples from fatal and nonfatal cases of Ebola (Sudan) hemorrhagic fever: cellular responses, virus load, and nitric oxide levels. J Virol 78(19):10370-10377

4. Ilesanmi O, Alele FO (2016) Knowledge, attitude and perception of Ebola virus disease among secondary school students in Ondo State, Nigeria, October, 2014. PLoS Curr 8: ecurrents.outbreaks. c04b88cd5cd03cccb99e125657eecd76

5. Crisis update-November (2018) https://www.msf.org/drc2018-ebola-outbreak-crisis-update Accessed 5 Jan 2019

6. Brauburger K, Boehmann Y, Tsuda Y, Hoenen T, Olejnik J, Schumann M, Ebihara H, Muhlberger E (2014) Analysis of the highly diverse gene borders in Ebola virus reveals a distinct mechanism of transcriptional regulation. J Virol 88(21):12558-12571

7. Sun Y, Guo Y, Lou Z (2012) A versatile building block: the structures and functions of negative-sense single-stranded RNA virus nucleocapsid proteins. Protein Cell 3(12):893-902

8. Huang Y, Xu L, Sun Y, Nabel GJ (2002) The assembly of Ebola virus nucleocapsid requires virion-associated proteins 35 and 24 and posttranslational modification of nucleoprotein. Mol Cell 10(2):307-316

9. Trunschke M, Conrad D, Enterlein S, Olejnik J, Brauburger K, Muhlberger E (2013) The L-VP35 and L-L interaction domains reside in the amino terminus of the Ebola virus $\mathrm{L}$ protein and are potential targets for antivirals. Virology 441(2):135-145

10. Su Z, Wu C, Shi L et al (2018) Electron cryo-microscopy structure of Ebola virus nucleoprotein reveals a mechanism for nucleocapsid-like assembly. Cell 172(5):966-978

11. Kirchdoerfer RN, Abelson DM, Li S, Wood MR, Saphire EO (2015) Assembly of the Ebola virus nucleoprotein from a chaperoned VP35 complex. Cell Rep 12(1):140-149

12. Dong S, Yang P, Li G, Liu B, Wang W, Liu X, Xia B, Yang C, Lou Z, Guo Y, Rao Z (2015) Insight into the Ebola virus nucleocapsid assembly mechanism: crystal structure of Ebola virus nucleoprotein core domain at 1.8 A resolution. Protein Cell 6(5):351-362

13. Wilson JA, Bray M, Bakken R, Hart MK (2001) Vaccine potential of Ebola virus VP24, VP30, VP35, and VP40 proteins. Virology 286(2):384-390

14. Sakabe S, Sullivan BM, Hartnett JN et al (2018) Analysis of CD8 ${ }^{+}$ T cell response during the 2013-2016 Ebola epidemic in West Africa. Proc Natl Acad Sci USA 115(32):E7578-E7586

15. Herbert AS, Kuehne AI, Barth JF et al (2013) Venezuelan equine encephalitis virus replicon particle vaccine protects nonhuman primates from intramuscular and aerosol challenge with ebolavirus. J Virol 87(9):4952-4964

16. Swenson DL, Wang D, Luo M, Warfield KL, Woraratanadharm J, Holman DH, Dong JY, Pratt WD (2008) Vaccine to confer to nonhuman primates complete protection against multistrain Ebola and Marburg virus infections. Clin Vccine Immunol 15(3):460-467

17. Martins KA, Jahrling PB, Bavari S, Kuhn JH (2016) Ebola virus disease candidate vaccines under evaluation in clinical trials. Expert Rev Vaccines 15(9):1101-1112

18. Lohia N, Baranwal M (2014) Conserved peptide containing overlapping CD4 + and CD8 + T cell epitopes in H1N1 influenza virus: An immunoinformatics approach. Viral Immunol 27(5):225-234

19. Sirskyj D, Diaz-Mitoma F, Golshani A, Kumar A, Azizi A (2011) Innovative bioinformatic approaches for developing peptidebased vaccines against hypervariable viruses. Immunol Cell Biol 89(1):81-89

20. Hossain MU, Keya CA, Das KC, Hashem A, Omar TM, Khan MA, Rakib-Uz-Zaman SM, Salimullah M (2018) An immunopharmacoinformatics approach in development of vaccine and drug candidates for West Nile Virus. Front Chem 6(246). https ://doi.org/10.3389/fchem.2018.00246

21. Ali MT, Islam MO (2015) A highly conserved GEQYQQLR epitope has been identified in the nucleoprotein of Ebola virus by using an in silico approach. Adv Bioinformatics 2015:278197. https://doi.org/10.1155/2015/278197

22. Lohia N, Baranwal M (2017) Immune response of highly conserved influenza A virus matrix 1 peptides: matrix 1 peptides for influenza vaccine. Microbiol Immunol 61(6):225-231

23. Afley P, Dohre SK, Prasad GB, Kumar S (2015) Prediction of T cell epitopes of Brucella abortus and evaluation of their protective role in mice. Appl Microbiol Biotechnol 99(18):7625-7637

24. Bounds CE, Terry FE, Moise L, Hannaman D, Martin WD, De Groot AS, Suschak JJ, Dupuy LC, Schmaljohn CS (2017) An immunoinformatics-derived DNA vaccine encoding human class II T cell epitopes of Ebola virus, Sudan virus, and Venezuelan equine encephalitis virus is immunogenic in HLA transgenic mice. Hum Vaccin Immunother 13(12):2824-2836

25. Edgar RC (2004) MUSCLE: multiple sequence alignment with high accuracy and high throughput. Nucleic Acids Res 32(5):1792-1797

26. Miotto O, Heiny A, Tan TW, August JT, Brusic V (2008) Identification of human-to-human transmissibility factors in $\mathrm{PB} 2$ proteins of influenza A by large scale mutual information analysis. BMC Bioinformatics 9(1):18

27. Dhiman G, Lohia N, Jain S, Baranwal M (2016) Metadherin peptides containing $\mathrm{CD}^{+}$and $\mathrm{CD} 8^{+} \mathrm{T}$ cell epitopes as a therapeutic vaccine candidate against cancer. Microbiol Immunol 60(9):646-652

28. Rammensee H, Bachmann J, Emmerich NP, Bachor OA, Stevanovic S (1999) SYFPEITHI: database for MHC ligands and peptide motifs. Immunogenetics 50(3-4):213-219

29. Larsen MV, Lundegaard C, Lamberth K, Buus S, Lund O, Nielsen M (2007) Large-scale validation of methods for cytotoxic T-lymphocyte epitope prediction. BMC Bioinformatics $8: 424$

30. Nielsen M, Lundegaard C, Lund O (2007) Prediction of HLA class II binding affinity using SMMalign, a novel stabilization matrix alignment method. BMC Bioinformatics 8:238

31. Bhasin M, Raghava GP (2004) SVM based method for predicting HLA-DRB $1 * 0401$ binding peptides in an antigen sequence. Bioinformatics 20(3):421-423

32. Singh H, Raghava GP (2001) ProPred: prediction of HLA-DR binding sites. Bioinformatics 17(12):1236-1237 
33. Saha S, Raghava GP (2006) Prediction of continuous B-cell epitopes in an antigen using recurrent neural network. Proteins 65(1):40-48

34. Saha S, Raghava GPS (2006) AlgPred: prediction of allergenic proteins and mapping of IgE epitopes. Nucleic Acids Res 34:W202-W209

35. Kurcinski M, Jamroz M, Blaszczyk M, Kolinski A, Kmiecik S (2015) CABS-dock web server for the flexible docking of peptides to proteins without prior knowledge of the binding site. Nucleic Acids Res 43(W1):W419-W424

36. Lohia N, Baranwal M (2018) Highly conserved hemagglutinin peptides of H1N1 influenza virus elicit immune response. 3 Biotech 8(12):492. https://doi.org/10.1007/s13205-018-1509-3

37. Arango MT, Perricone C, Kivity S, Cipriano E, Ceccarelli F, Valesini G, Shoenfeld Y (2017) HLA-DRB1 the notorious gene in the mosaic of autoimmunity. Immunol Res 65(1):82-98

38. Nikbin B, Nicknam MH, Hadinedoushan H, Ansaripour B, Moradi B, Yekaninejad M, Aminikhah M, Ranjbar MM, Amirzargar A (2017) Human leukocyte antigen (HLA) class I and II polymorphism in Iranian healthy population from Yazd Province. Iran J Allergy Asthma Immunol 16(1):1-13

39. Wieczorek M, Abualrous ET, Sticht J, Álvaro-Benito M, Stolzenberg S, Noé F, Freund C (2017) Major histocompatibility complex (MHC) class I and MHC class II proteins: conformational plasticity in antigen presentation. Front Immunol 8(292). https://doi.org/10.3389/fimmu.2017.00292

40. Blaszczyk M, Kurcinski M, Kouza M, Wieteska L, Debinski A, Kolinski A, Kmiecik S (2016) Modeling of protein-peptide interactions using the CABS-dock web server for binding site search and flexible docking. Methods 93:72-83

41. Li W, Joshi MD, Singhania S, Ramsey KH, Murtl AK (2014) Peptide vaccine: progress and challenges. Vaccines 2:515-536

42. Francis JN, Bunce CJ, Horlock C, Watson JM, Warrington SJ, Georges B, Brown CB (2015) A novel peptide-based pan-influenza A vaccine: a double blind, randomised clinical trial of immunogenicity and safety. Vaccine 33(2):396-402

43. Zom GG, Welters MJP, Loof NM et al (2016) TLR2 ligandsynthetic long peptide conjugates effectively stimulate tumordraining lymph node $\mathrm{T}$ cells of cervical cancer patients. Oncotarget 7(41):67087-67100

44. Agallou M, Athanasiou E, Koutsoni O, Dotsika E, Karagouni E (2014) Experimental validation of multi-epitope peptides including promising MHC Class I- and II-restricted epitopes of four known Leishmania infantum proteins. Front Immunol 5(268). https://doi.org/10.3389/fimmu.2014.00268

45. Vani J, Shaila MS, Chandra NR, Nayak R (2006) A combined immuno-informatics and structure-based modeling approach for prediction of $\mathrm{T}$ cell epitopes of secretory proteins of Mycobacterium tuberculosis. Microbes Infect 8(3):738-746

46. Lohia N, Baranwal M (2015) Identification of conserved peptides comprising multiple $\mathrm{T}$ cell epitopes of matrix 1 protein in H1N1 influenza virus. Viral Immunol 28(10):570-579

47. Dikhit MR, Kumar A, Das S, Dehury B, Rout AK, Jamal F, Sahoo GC, Topno RK, Pandey K, Das VNR, Bimal S, Das P (2017) Identification of Potential MHC Class-II-restricted epitopes derived from Leishmania donovani antigens by reverse vaccinology and evaluation of Their CD4 + T-cell responsiveness against visceral leishmaniasis. Front Immunol 8(1763). https://doi.org/10.3389/fimmu.2017.01763

48. Yassin GM, Amin MA, Attia AS (2016) Immunoinformatics identifies a lactoferrin binding protein a peptide as a promising vaccine with a global protective prospective against moraxella catarrhalis. J Infect Dis 213(12):1938-1945

49. Sundar K, Boesen A, Coico R (2007) Computational prediction and identification of HLA-A2.1-specific Ebola virus CTL epitopes. Virology 360(2):257-263
50. Dutta DK, Rhodes K, Wood SC (2015) In silico prediction of Ebola Zaire GP $(1,2)$ immuno-dominant epitopes for the Balb/c mouse. BMC Immunol 16:59. https://doi.org/10.1186/s1286 5-015-0126-8

51. Dikhit MR, Kumar S, Vijaymahantesh et al (2015) Computational elucidation of potential antigenic CTL epitopes in Ebola virus. Infection Genetics and Evolution 36:369-375

52. Ruibal P, Oestereich L, Lüdtke A et al (2016) Unique human immune signature of Ebola virus disease in Guinea. Nature 533(7601):100-104

53. Theaker SM, Rius C, Greenshields-Watson A, Lloyd A, Trimby A, Fuller A, Miles JJ, Cole DK, Peakman M, Sewell AK, Dolton $\mathrm{G}$ (2016) T-cell libraries allow simple parallel generation of multiple peptide-specific human T-cell clones. J Immunol Methods 430:43-50

54. Gupta M, Greer P, Mahanty S, Shieh WJ, Zaki SR, Ahmed R, Rollin PE (2005) CD8-Mediated Protection against Ebola Virus Infection Is Perforin Dependent. J Immunol 174(7):4198-4202

55. Simmons G, Lee A, Rennekamp AJ, Fan X, Bates P, Shen H (2004) Identification of murine T-cell epitopes in Ebola virus nucleoprotein. Virology 318(1):224-230

56. Wilson JA, Hart MK (2001) Protection from Ebola virus mediated by cytotoxic $\mathrm{T}$ lymphocytes specific for the viral nucleoprotein. $\mathrm{J}$ Virol 75(6):2660-2664

57. Fritsche PJ, Helbling A, Ballmer-Weber BK (2010) Vaccine hypersensitivity-update and overview. Swiss Med Wkly 140(17-18):238-246

58. Cohen AD, Shoenfeld Y (1996) Vaccine-induced autoimmunity. J Autoimmun 9(6):699-703

59. Meyboom RH, Fucik H, Edwards IR (1995) Thrombocytopenia reported in association with hepatitis B and A vaccines. Lancet 345(8965): 1638

60. Topaloglu H, Berker M, Kansu T, Saatci U, Renda Y (1992) Optic neuritis and myelitis after booster tetanus toxoid vaccination. Lancet 339(8786): 178-179

61. Patja A, Mäkinen-Kiljunen S, Davidkin I, Paunio M, Peltola H (2001) Allergic reactions to measles-mumps-rubella vaccination. Pediatrics 107(2):E27

62. Businco L (1994) Measles, mumps, rubella immunization in eggallergic children: a long-lasting debate. Ann Allergy 72(1):1-3

63. Atsmon J, Kate-Ilovitz E, Shaikevich D, Singer Y, Volokhov I, Haim KY, Ben-Yedidia T (2012) Safety and immunogenicity of multimeric-001-a novel universal influenza vaccine. J Clin Immunol 32(3):595-603

64. Hou Y, Guo Y, Wu C, Shen N, Jiang Y, Wang J (2012) Prediction and identification of $\mathrm{T}$ cell epitopes in the $\mathrm{H} 5 \mathrm{~N} 1$ influenza virus nucleoprotein in chicken. PLoS One 7(6):e39344

65. Tawar RG, Duquerroy S, Vonrhein C et al (2009) Crystal structure of a nucleocapsid-like nucleoprotein-RNA complex of respiratory syncytial virus. Science 326(5957):1279-1283

66. Yabukarski F, Lawrence P, Tarbouriech N, Bourhis JM, Delaforge E, Jensen MR, Ruigrok RW, Blackledge M, Volchkov V, Jamin M (2014) Structure of Nipah virus unassembled nucleoprotein in complex with its viral chaperone. Nat Struct Mol Biol 21(9):754-759

67. Alayyoubi M, Leser GP, Kors CA, Lamb RA (2015) Structure of the paramyxovirus parainfluenza virus 5 nucleoprotein-RNA complex. Proc Natl Acad Sci USA 112(14):E1792-E1799

68. He Y, Li J, Mao W et al (2018) HLA common and well-documented (CWD) alleles in China. HLA https://doi.org/10.1111/ $\tan .13358$

69. Robinson J, Halliwell JA, Hayhurst JD, Flicek P, Parham P, Marsh SG (2015) The IPD and IMGT/HLA database: allele variant databases. Nucleic Acids Res 43:423-431 
70. Kalyanaraman N (2018) In silico prediction of potential vaccine candidates on capsid protein of human bocavirus 1. Mol Immunol 93:193-205

71. Watanabe S, Noda T, Kawaoka Y (2006) Functional mapping of the nucleoprotein of Ebola virus. J Virol 80(8):3743-3751

72. Albertini AA, Wernimont AK, Muziol T, Ravelli RB, Clapier CR, Schoehn G, Weissenhorn W, Ruigrok RW (2006) Crystal structure of the rabies virus nucleoprotein-RNA complex. Science 313(5785):360-363

73. Noda T, Hagiwara K, Sagara H, Kawaoka Y (2010) Characterization of the Ebola virus nucleoprotein-RNA complex. J Gen Virol 91(6):1478-1483

74. Medaglini D (2018) Correlates of vaccine-induced protective immunity against Ebola virus disease. Semin Immunol. https:// doi.org/10.1016/j.smim.2018.07.003

75. Henao-Restrepo AM, Camacho A, Longini IM et al (2017) Efficacy and effectiveness of an rVSV-vectored vaccine in preventing Ebola virus disease: final results from the Guinea ring vaccination, open-label, cluster-randomised trial (Ebola Ça Suffit!). Lancet 389(10068):505-518
76. Halperin SA, Arribas JR, Rupp R, Andrews CP, Chu L, Das R, Simon JK, Onorato MT, Liu K, Martin J, Helmond FA (2017) Sixmonth safety data of recombinant vesicular stomatitis virus-zaire ebola virus envelope glycoprotein vaccine in a phase 3 doubleblind, placebo-controlled randomized study in healthy adults. J infect Dis 215(12):1789-1798

77. Ledgerwood JE, DeZure AD, Stanley DA et al (2017) Chimpanzee Adenovirus Vector Ebola Vaccine. N Engl J Med 376(10):928-938

78. Ewer K, Rampling T, Venkatraman N et al (2016) A monovalent chimpanzee adenovirus ebola vaccine boosted with MVA. N Engl J Med 374(17):1635-1646

Publisher's Note Springer Nature remains neutral with regard to jurisdictional claims in published maps and institutional affiliations. 